\title{
Leitura, experiência e conflito em "O embrulho da carne"
}

\author{
Helenice Fragoso dos Santos ${ }^{1}$ \\ Gilda Albuquerque de Vilela Brandão ${ }^{2}$
}

\section{Resumo}

Refletir sobre a atividade de leitura como experiência marcada pela perplexidade provocada pelo contato com uma manchete policial, vivida pela protagonista do conto o Embrulho da Carne de Sérgio Sant'Anna (2003) - a partir das considerações de Jorge Garcia Larrosa (2002) sobre experiência e o saber da experiência - é a principal proposta deste trabalho. O interesse em aproximar a noção de experiência da ideia leitura justifica-se pelo fato de que o gesto de ler figurado no conto, além de funcionar como força de conflito, atua como agente mobilizador do curso da narrativa. Para tanto tomamos como escopo teórico as considerações de: a) Alfredo Bosi (1975) - no que se refere ao entendimento do conto contemporâneo brasileiro como uma espécie de poliedro; b) Bernardo Gustavo (2010) - quanto à presentificação do fenômeno da metaficção.

Palavras-chave: Leitura. Experiência. Conflito.

\begin{abstract}
Reflecting on the act of reading as an experience, highlighted in the bewilderment of Sérgio Sant'Anna's protagonist in his work, "Embrulho da Carne," as he encounters a police headline - especially when taking Jorge Garcia Larrosa's considerations (2002) on experience and knowledge of experience into account - is the primary purpose of this piece. The importance of relating the notion of experience - originally proposed by Larrosa (2002 ) - and the idea of reading is justified by the fact that the act of reading as it is presented in the story, not only function as a source of conflict but also acts as a mobilizing agent over the course of the narrative. We will be taking the work of Alfredo Bosi (1975) as our theoretical scope with regard to the understanding of contemporary Brazilian tale as a kind of polyhedron.
\end{abstract}

Keywords: Reading. Experience. Conflict.

\footnotetext{
${ }^{1}$ Doutoranda em Estudos Literários pela Universidade Federal de Alagoas. E-mail: nicefragoso@hotmail.com.

${ }^{2}$ Professora em Literatura brasileira e Literatura francesa pela Universidade Federal de Alagoas. E-mail: gildabrandao@gmail.com.
}

Revista Leitura v.2 no 54 - Júlio/Dez 2014 - Número temático: Leituras interartes. 
Dentre as várias significações que a palavra experimentar apresenta e que se relacionam ao poema acima, temos a ideia de provar, degustar e saborear. Daí talvez a menção ao termo delícia no penúltimo verso que nos remonta à dimensão sensorial do paladar e nos leva a considerar que experimentar é, entre outras coisas, deliciar-se com aquilo que saboreamos num dado momento.

No discurso inaugural da cadeira de semiologia literária do Colégio de França, Roland Barthes (1978) lembra que as palavras sabor e saber, em latim, possuem a mesma raiz etimológica. Tal recordação nos mostra que a experiência do saber compreende a possibilidade de contato com o sabor de algo que nos afeta em diversas dimensões como lembram os versos acima ao trazer a figura de um sujeito sensível à experiência da dor nas múltiplas dimensões sensoriais - seja por intermédio da visão ("ver"/ “é dor”), da audição (“ouvir”/ “é dor”) ou do paladar (“delícia”/ "de experimentador") - E que, portanto, este sujeito vive o risco do sofrimento em ganhos ("ter"/ "é dor") e faltas ("perder"/ "é dor") captadas pelo gesto de ver, ouvir e se deliciar.

Há de se observar ainda, que a recorrência sonora do substantivo "dor" reforça o fato de o adjetivo que encerra o poema comportar essa palavra. O sujeito que experimenta, nos diz os versos, traz na própria denominação a possibilidade de sofrimento.

A proposta deste trabalho é pensar a atividade de leitura como experiência marcada pela perplexidade causada pelo contato com uma manchete policial vivida pela protagonista do conto o "Embrulho da Carne" de Sérgio Sant'Anna, a partir das considerações de Jorge Garcia Larrosa (2002) sobre experiência e o saber da experiência. 
Tal interesse também revela o risco da dor e do equívoco, uma vez que nosso objeto de investigação compreende um sujeito ficcional. No entanto, abraçamos os riscos, dores e sabores, que compreendem aventurar-se pelas trilhas da ficção assumindo o lugar de experimentador.

\section{A personagem como sujeito da experiência}

Ao refletir sobre a educação a partir da ideia de experiência e do saber da experiência - sob o ponto de vista da travessia, do perigo, da abertura, da exposição, da receptividade, da transformação e da paixão - Larrosa (2002) abre seu discurso revelando a crença na potencialidade da palavra: "Eu creio no poder das palavras, na força das palavras, creio que fazemos coisas com as palavras e, também, que as palavras fazem coisas conosco" (p.21). Tal confissão promove um questionamento sobre até que ponto um sujeito é afetado pela palavra enquanto experiência de leitura de um texto.

No conto "O embrulho da carne" o escritor carioca Sérgio Sant'Anna (2003) parece problematizar tal questão, ao trazer para o cerne da narrativa uma protagonista cuja trajetória é profundamente abalada pela experiência de leitura.

A fim de entendermos tal alcance, pensemos na sucessão de fatos apresentados a seguir: Imaginemos uma mulher que desejando preparar um jantar a dois, dirige-se ao açougue para obter o elemento que servirá como principal ingrediente ao preparo de um estrogonofe. Acrescentemos, aliás, um conflito: esta mulher que não tolera carne, tampouco o ambiente no qual é comercializada, enfrenta esta dupla repulsa e, só então, adquire o produto. Este, porém, lhe é entregue embrulhado numa folha de jornal que noticiara uma história de assassinato e violência sexual. A protagonista, então, decide lê a reportagem, cuja brutalidade faz com que seus traumas e incertezas venham à tona. É o que revela diante de seu analista:

[...] É tudo muito complicado, porque também pensei em jogar o jornal pela janela do meu quarto, mas que sujeira eu ia fazer; (sarcástica) o que os vizinhos iriam pensar? Mas a outra verdade - a verdade mesmo, eu acho - é que eu só tinha visto a fotografia e passado os olhos na reportagem e precisava ler aquela notícia, do princípio ao fim, como se fosse covardia, ou uma traição à moça morta, se eu não lesse. É isso. Se a moça tinha passado por aquilo tudo, eu tinha no mínimo, obrigação de saber tudo, saber como são coisas. (SANT'ANNA, 2003, p.62) 
Sob a tensão de simplesmente ignorar o texto e a justificativa dos interesses que motivaram à procura deste, a fala de Teresa parece denunciar um comportamento comum em nossos tempos: a dificuldade de o sujeito moderno de sentir-se tocado por fatos corriqueiros em detrimento à pressa que marca seu cotidiano, sempre mergulhado numa inesgotável gama de informações. Traço que segundo Larrosa (2002), assim como o excesso de opinião, o periodismo e falta de tempo concorrem à noção de experiência:

[...] A experiência é cada vez mais rara, por falta de tempo. Tudo que se passa passa demasiadamente depressa, cada vez mais depressa. E com isso se reduz o estímulo fugaz e instantâneo, imediatamente substituído por outro estímulo fugaz e instantâneo ou por outra excitação igualmente fugaz e efêmera. (LARROSA, 2002, p. 23)

Longe de seguir adiante e ignorar os fatos presentes no embrulho, a personagem do conto de Sérgio Sant'Anna mostra-se sensível à história do jornal ao desestabilizar-se tanto no plano físico quanto no psicológico:

[...] Meu coração pulava pela boca, mas deitei na cama, abri o jornal e fui lendo os detalhes, um por um: que era uma moça humilde, de vinte anos, presumivelmente, com roupas surradas e calçando um velho tênis cor-de-rosa, com um buraco na sola. Isso, no tênis que ainda estava no pé dela, porque o outro estava caído no chão do vagão, junto com a calcinha, a miniblusa e o sutiã. Segundo os policiais, ela provavelmente fora atraída por um homem para um encontro amoroso no vagão do trem abandonado, o trem fantasma, que serve de abrigo para mendigos, marginais e viciados em drogas, conforme $\mathrm{o}$ depoimento dos moradores da região. (SANT'ANNA, 2003, p. 62)

A reação da personagem à leitura do texto se aproxima da ideia de sujeito da experiência de Larrosa (2002, p. 24) na medida em que: “[...] o sujeito da experiência é sobretudo um espaço onde têm lugar os acontecimentos". Nesse sentido, a escrita sant'anniana parece legar à personagem a condição de sujeito da experiência de leitura, visto que, ainda que no campo da ficção, essa personagem não compreende "[...] um sujeito que permanece sempre em pé, ereto, erguido e seguro de si [...], mas um sujeito que perde seus poderes precisamente porque aquilo de que faz experiência dele se apodera" (LARROSA, 2002, p. 25).

Nessa perspectiva, "O embrulho da carne" se revela como possibilidade de pensar a personagem enquanto sujeito da experiência, sob justificativa de que a leitura vivenciada pela protagonista compreende uma força de caráter irreversível e particular. 
Sobretudo, porque nos termos de Larrosa (2002) a experiência compreende um fenômeno que encontra no sujeito, e não em torno deste, um lugar privilegiado: "A experiência é aquilo que nos passa, o que nos acontece, o que nos toca. Não o que se passa, não o que acontece, ou o que toca" (LARROSA, 2002, p.21).

Daí a justificativa de aproximar a noção de experiência da ideia de leitura, visto que o gesto de ler, figurado no conto, além de desestabilizar a personagem, também funciona como dinâmica que mobiliza o próprio curso da narrativa enquanto força de conflito.

\section{A leitura como força de conflito}

A ideia de um voo rasante durante a madrugada parece sintetizar o imaginário do escritor carioca Sérgio Sant'Anna. Em "O vôo da madrugada”, coletânea de contos publicada em 2003, a obscuridade da noite, que atravessa a nitidez do olhar, é perceptível não apenas nos temas, muitas vezes, de cunho transgressor, mas é sentida na própria edificação da obra.

Um voo cuja principal travessia apresenta como roteiros cenários de ambientações urbanas, por intermédio de uma escrita que conduz o leitor a descobrir, num espaço imerso pela obscuridade noturna, toda atmosfera de mistérios e segredos.

Uma travessia arriscada guiada por uma linguagem que formaliza o clima de tensão, erotismo e desejos obscuros mediante estratégia de narração que, além de chamar atenção para seu modo de composição, apresenta uma velocidade nas aparições de personagens, memórias e alucinações.

A presentificação da violência, drogas, poluição sonora e visual a envolver o quotidiano das personagens funciona como um fator de oposição aos interesses desses sujeitos. A paisagem urbana, por exemplo, além de atuar como pano de fundo no curso das tramas também opera como força de conflito, ou seja, como elemento da narrativa que apresenta relação direta com o desenrolar das ações, compreendendo uma espécie de potência capaz de interferir no curso dos eventos, operando como elemento mobilizador de fatos, correspondente desencadeando“[...] a oposição, a luta, a tensão entre duas forças ou personagens. Por meio dele, a ação se organiza e progride até o desfecho [...]”. (MOISÉS, 2004, p. 84).

Enquanto elemento transformador da narrativa, o surgimento do conflito provoca um estado de tensão que altera o equilíbrio das ações acrescentando uma série 
de contornos à trama. Para João Hilton Siqueira (1992), o conflito é o componente que diferencia a narrativa ficcional de um simples relato, na medida em que seu: “[...] aparecimento provoca uma quebra na expectativa inicial e faz a narrativa ganhar novo rumo ou novos rumos" (1992, p. 15).

A escrita de Sant'Anna, na obra $O$ vôo da madrugada (2003), revela-se engenhosa porque promove uma curiosa articulação entre o surgimento dos conflitos com o caráter estrutural da trama, de modo que a presença destas forças ultrapassam a dimensão das personagens em seu contexto temático, mostrando-se perceptível na própria tessitura do texto: seja quanto à disposição do foco narrativo, seja nas imbricações estabelecidas entre elementos estruturados de tempo e espaço.

No conto "O Embrulho da Carne", por exemplo, a situação mobilizadora dos conflitos de Teresa, personagem central desta trama, dá-se a partir do contato da protagonista com uma folha de jornal que serve de embalagem à carne adquirida no açougue. Esta situação - que aproxima a ojeriza que a personagem sente pelo ambiente do açougue ao choque causado em decorrência da notícia - provoca na protagonista um misto de repugnância pelo alimento e fascínio pela manchete policial.

A partir desse jogo simbólico que oscila entre o sentimento de repulsa à carne e o interesse pela notícia de jornal, a narrativa confirma as considerações de Alfredo Bosi (1975), no que diz respeito à capacidade de conjugação das duas qualidades de situação - "real" ou "imaginária" - presentes no conto contemporâneo brasileiro para as quais convergem os acontecimentos narrados.

Entre o real e imaginário, assim caminha a escrita deste conto cujo foco narrativo dedica-se a explorar uma situação que envolve, conforme os termos de Bosi (1975), tanto um dado do real - na medida em que o escritor toma como mote da trama manchetes de jornal ${ }^{3}$, quanto um situação se reveste de teor imaginário, visto que o autor ao ficcionalizar tais acontecimentos promove o surgimento de novas tramas.

É interessante observar a opção de Alfredo Bosi (1975) pelo emprego do termo situação, visto que estabelece uma relação de contiguidade com a palavra "ação", elemento constituinte da narrativa que, segundo Moisés (2004):

[...] O vocábulo "ação" designa a sequência de acontecimentos ou atos no transcurso de um conto, novela, romance, peça teatral ou poema

\footnotetext{
${ }^{3}$ Ao término do conto, Sant'Anna (2003) apresenta uma nota esclarecendo que "O embrulho da carne" fora inspirado em recortes de Jornais.

Revista Leitura v.2 no 54 - Júlio/Dez 2014 - Número temático: Leituras interartes. 
narrativo. [...] Nas estruturas narrativas (conto, novelas, romance) duas modalidades de ação podem ser observadas: a ação exterior, quando as personagens se movem no tempo e no espaço; e a ação interior, quando o conflito transcorre na sua mente. (p.10)

Em "O embrulho da carne" a escrita sant'anniana comporta as duas modalidades ação, com maior recorrência da segunda, na qual há exploração da psique da personagem. Este conto, inclusive, inicia-se numa sessão psicanalítica, o que reforça a tese de que o plano psíquico alcança um campo privilegiado.

É mediante a exploração da experiência de leitura da personagem -confisssões e devaneios - que as ações transcorrem na trama operacionalizando espaços e eventos numa espécie de reação em cadeia.

Os ambientes são apresentados via impressões da personagem, cuja memória promove uma profusão de imagens que retomam cenários e deslocam o foco narrativo para a apresentação de circunstâncias que comportam toda profundidade dramática dos espaços e reforçam a carga emocional das confissões de Teresa, que parece ficcionalizar sua experiência de leitura deslocando o foco narrativo para o cenário do crime. De modo que é possível perceber a tentativa da personagem em atribuir voz à vítima, por intermédio, do discurso direto:

Teresa não consegue mais reter as lágrimas enquanto fala.

- Você já pensou no terror que ela deve ter sentido ao ser estuprada e morta? E ela deve ter pedido: "Pelo amor de Deus, não me matem". [...]. (SANT'ANNA, 2003, p. 63.).

Em suas confissões, Teresa não só apresenta sua experiência de leitura como tenta reerabolá-las, ao criar uma possível fala para a vítima, uma fala que ela própria constrói , formalmente, em discurso direto e a reproduz para o analista.

Fator de interferência aos interesses da protagonista, a experiência de leitura nesta narrativa revela-se como elemento complicador que não a permite vivenciar plenamente os acontecimentos, atuando como um agente contrário às suas pretensões.

Quanto mais a personagem busca vivenciar o presente e a fruição de um possível jantar a dois, mais sua experiência de leitura funciona como um fator de intervenção. Seja na retomada de problemas existenciais não resolvidos, presentificados nas lembranças de um matrimônio desfeito e maternidade não concretizada, seja na explicitação de suas frustrações, medos e traumas não superados. 
Principal força de opressão e coerção das potencialidades da personagem, a experiência de leitura revela-se no curso da narrativa como um agente de profunda perturbação.

Nesse sentido, o contato de Teresa com recorte de jornal encena a possibilidade de conexão da personagem com ela mesma. O embrulho da carne signa a própria subjetividade da personagem numa espécie de busca por entendimento de si, do outro, e, por conseguinte, do mundo.

A identificação da personagem com um fato externo promove um jogo metonímico recorrente na narrativa, já que se enxergar como pedaço de carne, a personagem enseja o sofrimento do animal que fora abatido e, numa dimensão mais ampla, do próprio homem. Diz a personagem:

[...] Não consigo entrar num açougue achando tudo natural. Quer dizer, natural até que é, por que a vida é exatamente assim, uns devorando os outros, só que eu tenho consciência disso o tempo todo e as outras pessoas não [...]. (SANT’ANNA, 2003, p. 58)

O jornal, ao que parece, simula na narrativa uma metáfora do espelho no qual Teresa vê projetada diante de si a própria imagem. Assim como Narciso - figura mitológica da tradição grega que não consegue distinguir-se de mero reflexo - a personagem apresenta dificuldades em estabelecer um distanciamento dos fatos relacionados à notícia policial:

[...] Eu posso ser uma burguesinha fresca que faz análise, mas, de repente, aquela moça enforcada era eu, entende? E muito mais do que você imagina. Porque eu era ela até fisicamente, pois minha mão estava suja da tinta do jornal e engordurada da carne. Na pressa de sair da cozinha, nem lavei as mãos e, para mim, eu estava engordurada era da carne da moça. Ao mesmo tempo, era eu quem balançava, enforcada, na escuridão da noite num vagão abandonado. E não havia ninguém para vir em meu socorro; não havia ninguém comigo. (SANT'ANNA, 2003, p. 64)

Em face de um evento transformador ou, nos termos de Bosi (1975), de uma situação, a escrita de Sérgio Sant'Anna faz das lembranças da personagem uma espécie de cárcere na qual mantém a percepção dos fatos sem desviar a visão de si. Desta feita, a protagonista pouco a pouco vai se perdendo, não em águas, semelhantemente à figura mitológica de Narciso, mas na impossibilidade de desprendimento de si provocada pela 
tentativa frustrada de dissipar de sua memória a imagem de uma jovem brutalmente assassinada:

[...] E foi um impulso irresistível: peguei o isqueiro que estava ao lado do maço de cigarros, em cima da minha cama, e ateei fogo no jornal, assim bem debaixo da folha. Não sei se faz sentido para você, mas para mim faz todo: eu queria que aquela imagem e aquela notícia e meus pensamentos desaparecessem, então só podia ser com o fogo. Porque o fogo consome e purifica tudo. Está aí a explicação de por que eu quase toquei fogo no meu quarto.

- Queimou muita coisa Teresa?

- Queimou bastante a roupa de cama e um pouco do colchão, pois quando a chama cresceu e ia queimar minhas mãos, eu tive que pular da cama e largar o jornal. Mas se não fosse a Neuza me sacudir, podia ter queimado muito mais. Eu estava paralisada, só conseguia gritar [...] (SANT'ANNA, 2003, p. 64).

O gesto de provocar, ainda que acidentalmente, incêndio no colchão soa como uma metáfora do desgaste da própria sexualidade e por conseguinte, como uma busca de compensação dessa dimensão.

A dificuldade de autocontrole da personagem é reforçada também pela eminência da regulação do tempo do discurso. Há um controle da fala durante sessão psicanalítica e a escrita sant'anniana incorpora esse senso de urgência na formalização do conto que acontece sob esta prerrogativa:

Ela pára de chorar e, aos poucos, vai conseguindo articular as palavras.

- ... o fogo, eu estava paralisada, hipnotizada. Eu só queria que a mulher enforcada desaparecesse sem deixar vestígios. Mas a chama cresceu e me descontrolei completamente e comecei a gritar pela Neuza.

- Pode contar mais devagar, Teresa, se você quiser. Reservei uma hora e meia pra você. (SANT'ANNA, 2003, p. 56.)

Uma hora e meia compreende o tempo estimado para relatar a complexidade de profusões de sensações que transcendem as formulações da lógica de convencional de tempo. É nesse sentido, que a escrita de Sant'Anna (2003) revela engenhosidade no tratamento deste elemento estruturador, ao orientar-se pela premissa temporal anunciada na duração da sessão psicanalítica. 
A complexidade temporal é fundada não só no modo como o narrador apresenta os fatos, mas se firma na constituição da psique da personagem, permeando o modo como os espaços são apresentados e deslocados pelo foco narrativo.

A repetição do nome da protagonista, por exemplo, é um modo de situar o ângulo de observação do narrador no micro espaço do consultório, ponto de partida dos devaneios de Teresa que se desdobra na apresentação de outros espaços.

Assim, o modo como os elementos estruturadores de tempo e espaço são articulados confirmam a hipótese de que a noção de conflito além de perpassar a dimensão temática, também se presentifica na estrutura da narrativa, cuja engrenagem confirma as considerações de Bosi (1975) sobre a compreensão do conto contemporâneo como uma espécie de poliedro - figura geométrica constituída por várias faces. Tal lembrança, também se aproxima da ideia da própria constituição do conto enquanto embrulho, ou seja, como uma superfície que apresenta vários afundamentos e ondulações nas suas estruturas temporais e espaciais.

\section{Metaficção: dobras, redobras e embrulhos}

Ao término de "O Embrulho da Carne", Sérgio Sant'Anna confessa aos interlocutores que a composição da trama teve como inspiração matérias de jornais publicadas no final da década de 80 , que noticiaram semelhante estória de assassinato figurada na narrativa. Em nota, diz o escritor: “[...] Este conto foi imaginado a partir de matérias, sobre o mesmo crime, publicado em O Dia e no Jornal do Brasil de 23.3.1987, [...]. Anotações foram feitas à época, guardei os recortes dos jornais, mas o texto só veio a ser escrito em 1999”. (SANT’ANNA, 2003, p. 71.)

Elaborado anos após o contato com as matérias do jornal, a produção deste conto revela a singularidade do exercício de escrita como resposta à experiência de leitura de outrora. Tal confissão permite-nos não somente refletir sobre seu modo de feitura, quanto pensar a atividade de escrita enquanto reverberação da leitura, cujo mote de composição revela-se enquanto um saber de experiência na medida em que, segundo Larrosa (2002), compreende o modo como se responde a um determinado estímulo: "Este é o saber da experiência: o que se adquire no modo como alguém vai respondendo ao que vai lhe acontecendo ao logo da vida e no modo como vamos dando sentido ao acontecer do que nos acontece" (LARROSA, 2002, p.27). 
A relação de contiguidade entre as leituras coexistentes que envolvem a figura do escritor, personagens e interlocutores, confirma o caráter metaficcional do conto, que de acordo com as considerações de Gustavo Bernardo (2010) quando compreende a capacidade que a ficção apresenta de se dobrar e redobrar internamente: “[...] Trata-se de um fenômeno estético autorreferente através do qual a ficção duplica-se por dentro, falando de si mesma ou contendo a si mesma" (BERNARDO, 2010, p.9). Mais adiante, ao tocar na problemática da metalinguagem enquanto duplicação de enigmas, o estudioso acrescenta: "Um dos mecanismos privilegiados de formulação ficcional de enigmas reside no fenômeno estético da metaficção, que por definição se dobra e se redobra de fora para dentro [...]" (p.13).

Inspirado na fotografia de Chema Madoz (1990), BERNARDO (2010) recorre à imagem do espelho como metáfora do fenômeno estético da metaficção. Segundo ele, a ficção compreende um espelhamento que inverte a realidade conduzindo a outros lugares, transcendendo o físico e a própria ficção:

Como sabemos há muito, o espelho da ficção não nos devolve a realidade refletida tal e qual: antes a inverte e depois nos leva para outro lugar. Este outro lugar se situa além da realidade de que partimos e além do espelho - além da ficção. Ora, "além da ficção" é uma tradução "ao pé da letra", digamos assim, da palavra "metaficção", porque o prefixo grego "meta" também pode significar "além de". (BERNARDO, 2010, p.9).

Associando tais considerações à recorrência do signo da leitura no conto, vemos que uma possibilidade de solução de seus conflitos estaria na privação da capacidade de ir "além do físico", "além do pensar", como ilustra o diálogo a seguir entre Teresa e seu analista:

- Mas aquele jornal que trazia uma cabeça degolada você parou na banca para ver, não foi, Teresa?

- Havia um grupinho de pessoas em frente à banca e fiquei curiosa. Algumas estavam rindo, e a manchete não deixava mesmo de ser engraçada: ACHARAM A CABEÇA. (Ela ri, nervosamente, e parece sentir um prazer compulsivo ao recontar a história.) E ali estava aquela cabeça, na vertical, em cima de uma mesa de sinuca. Os matadores haviam esquartejado o homem e espalharam os pedaços dele em locais diferentes, deixando bilhetinhos gozando a polícia. $\mathrm{Na}$ hora eu cheguei a rir um pouco, porque, de fato, havia um amor sinistro, quer dizer, um humor sinistro naquilo. Mas depois, quanto mais eu queria afastar aquela cabeça do meu pensamento, mais ela se grudava nele. Você sabe o que eu passei. Não gosto nem de lembrar. 
O doutor Elias sorri com bonomia.

- Você disse um amor sinistro, Teresa.

- Eu sei, eu percebi. Dou o braço a torcer.

- Você também me disse, na época, que sentia inveja daquela cabeça porque ela não pensava mais. (SANT'ANNA, 2003, p. 56.)

O sentimento de inveja sentida por um corpo decapitado é emblemático porque enseja a perda da faculdade de autoconsciência e, consequentemente, de acesso a outros modos de entendimento do mundo e de si. Desta feita, ao assumir o estágio de corpo degolado, a personagem tornar-se-ia fonte motivadora de prováveis manchetes policiais; deixando de ser apenas objeto de interesse de seu psicanalista.

Esse dobrado e redobrado, ou seja, o anseio por tornar-se objeto de leitura pela protagonista é o que, em certa medida, constitui um dos problemas da metaficção no conto, uma vez que: "Se toda linguagem é enigmática mesmo que não se queira assim, toda metalinguagem duplica o enigma ao tentar resolvê-lo. [...] o enigma se dobra e se redobra sobre si mesmo" (BERNARDO, 2010, p. 12-3).

Ao alertar o leitor sobre o fato de que o conto fora inspirado em recortes de jornal, a escrita sant'anniana ilustra as reverberações no âmbito da ficção de discursos fundados no real. Aproximação entre o discurso jornalístico e discurso ficcional recai numa tensão, já que o primeiro apresenta certo compromisso com o verídico tendo por finalidade atestar fatos do real, e o segundo atua sobre o campo das possibilidades e da invenção. Tais implicações promovem uma reflexão sobre o caráter ficcional contido em todo discurso já que, como ressalta Bernardo (2010), toda linguagem possui um caráter metafórico:

Nos livros didáticos, a metáfora costuma ser considerada apenas um recurso metafórico da ficção, quando se concentra a comparação entre dois termos em apenas um deles. No entanto, toda a linguagem pode ser percebida como metafórica, se as palavras não são as coisas que designam [...].

A metáfora surge sempre no lugar de outra coisa, precisamente daquilo que não se sabe. Se aceito o caráter metafórico de qualquer linguagem, preciso admitir que todo discurso é ficcional. Não digo, entretanto, que "tudo é ficção" nem que tudo seja relativo. Assim como é necessária uma referência absoluta para se estabelecer uma relação, o real continua necessário para que a ficção se construa a partir dele ou contra ele. Que o real exista não é minha questão; logo, não posso dizer que tudo seja ficção. Meu argumento é: temos acesso ao real através da mediação dos discursos; todo discurso elabora ficções aproximativas à realidade, portanto, todo discurso funda-se pela ficção; logo, todo discurso é ficcional. (BERNARDO, 2010, p.15). 
Reconhecendo que nem tudo é ficção, Bernardo (2010) confirma o caráter de não totalização do real pela linguagem, o qual defende Perrone Moisés (1990) ao justificar o impulso de criação literária como resposta à experiência da falta que atravessa a existência humana desde os primeiros momentos da vida. Ao nascermos, diz Perrone Moisés: “[...] o primeiro esforço para respirar e o choro emitido em consequência já evidencia a falta do conforto do útero materno" (PERRONE-MOISES, 1990, p. 103).

Diante do sentimento de insatisfação que permeia a vida, a Literatura surge como um mecanismo de reação à falta; inicialmente sentida no mundo e, num outro plano, na própria linguagem que não apreende o real em todas as suas dimensões: “[...] A literatura parte de um real que pretende dizer, falha ao dizê-lo, mas ao falhar diz outra coisa, desvenda um mundo mais real do que aquele que pretendia dizer" (PERRONEMOISES, 1990, p. 102).

De modo semelhante, Bernardo (2010) concebe o impulso ficcional enquanto modo de preenchimento de lacunas e indeterminações que perpassam a esfera humana: "Confrontando com as ameaças de fora (do mundo) e de dentro (de si mesmo), o ser humano reage fabulando: atribui sentido ao que se lhe apresenta sem sentido" (2010, p. 20).

Tal reação fabuladora se faz presente na fala de Teresa, quando aludindo ao episódio do crime reelabora/redobra para seu psicanalista um discurso interrompido e silenciado pela morte. A busca pelo entendimento dessas lacunas confere ao conto um caráter metafísico, ou seja, "além da física" que, como recorda Gustavo Bernardo (2010), compreende desde sua origem uma designação ao fenômeno da metaficção.

No conto examinado, as diferentes dobras e redobras metaficcionais resultam da analogia à própria constituição da matéria/jornal que toma forma de embrulho. Sendo assim, a imagem do objeto anunciado no título, confirma a configuração de seu caráter metanarrativo, na medida em que constitui matéria disforme que apresenta afundamentos e relevos, inclusive, na estrutura temporal estabelecida mediante desdobramentos da memória da personagem.

Ao cifrar a memória da personagem numa série de eventos, a escrita sant'anniana revela uma tensão de forças que movimentam as ações da trama, sobretudo pelo fato de que a ideia de memória envolve uma espécie de busca ou retorno a um momento que se perdeu, todavia, curiosamente apresenta algum grau de ambivalência, 
na medida em que se mostra acessível e inacessível ao mesmo tempo, já que é reinterpretado por outro instante que se insurge no momento da leitura.

A observação do método compositivo da narração é um aspecto que permite problematizar o lugar da escrita e da ficção. A evidenciação do modo de feitura do texto é recorrente e delega à escrita o papel de matéria prima no desenrolar das ações, figurando como um recurso autorreferente promovendo uma reflexão contínua sobre o processo de elaboração textual que escreve e se inscreve no curso da narrativa.

Os elementos estruturadores de tempo e espaço estão dispostos de modo bastante singular. O espaço vai sendo apresentado ao leitor via memória da personagem que surge como uma extensão de aspectos relacionados à dimensão temporal. $\mathrm{O}$ espaço no qual Teresa se submete à análise, por exemplo, confunde-se com outros espaços. De modo que as imbricações entre esses elementos provocam um efeito interessante que alude à irregularidade da superfície de um embrulho.

A imagem do embrulho não só ajuda a entender a estrutura composicional do conto, quanto atesta sua natureza autorreferente ao considerarmos a metáfora da dobra e redobra, proposta por Bernardo (2010), enquanto analogia ao mecanismo de formulação metaficcional fundada no fato de que um elemento externo que parte de um dado do real, ao ser transposto para a ordem da narração, torna-se efeito redobrado num “embrulho" que, por sua vez, será o evento transformador das ações no curso da trama.

Se para a personagem, a leitura do jornal teve como desdobramentos a busca de sentido para acontecimentos de sua existência, quando associamos este mesmo evento à figura do escritor percebemos que a leitura das matérias, ao tomar forma de conto, resultou na experiência de escrita que, por sua vez, tornar-se-á objeto de leitura.

Nessa perspectiva, as figuras envolvidas no processo de comunicação do conto: escritor, personagem e interlocutores compõem uma engrenagem fundada numa espécie de metaexperiência ao promover uma reflexão sobre a atividade de leitura, já que inspirado por notícias de jornais, o autor cria uma personagem atingida pelo mesmo evento, ao passo que os interlocutores da narrativa não só vive a experiência de apreensão do conto, quanto acompanha as peripécias de uma protagonista leitora criada a partir de semelhante gesto.

\section{Considerações finais}

Revista Leitura v.2 no 54 - Júlio/Dez 2014 - Número temático: Leituras interartes. 
A escrita sant'anniana, em "O embrulho da carne", traz como cerne literário a experiência de leitura enquanto fator de mobilização da trama, ao encenar a possibilidade de reconhecimento da protagonista com uma figura feminina objeto de matéria policial, já que a partir desse gesto eclodem no plano da fábula embates de ordem interpessoal e social.

Por intermédio da interlocução que se estabelece na sessão psicanalítica, a personagem tenta responder a esses conflitos. De modo que, é pelo discurso e no estabelecimento dos diálogos, ainda que regulados pelo tempo, com seu analista, que Teresa se recompõe.

Ao revelar que matérias jornalísticas funcionaram como motes de composição do conto - no qual a personagem de maior carga dramática é também leitora - Sérgio Sant'Anna (2003) torna o processo de feitura do texto objeto de reflexão, confirmando, desta feita, o caráter metaficcional da narrativa que se desvela aos olhos do leitor.

Assim, "leitura, experiência e conflito" se apresentam como índices de busca de entendimento de si, e, numa dimensão mais ampla, da própria existência humana, na medida em que a angústia apresentada pela personagem em relação a sua condição no mundo é, em certo grau, objeto de reflexão de todos.

\section{Referências}

BARTHES, Roland. Aula. Trad. Leyla Perrone Moisés. São Paulo: Cultrix, 1978. BERNARDO, Gustavo. O livro da metaficção. Rio de Janeiro: Tinta Negra Bazar Editorial, 2010.

BOSI, Alfredo. Situação e formas do conto brasileiro contemporâneo. In: BOSI, Alfredo.(Org.). O conto brasileiro contemporâneo. São Paulo: Cultrix/ EDUSP, 1975, p. 7-22.

LARROSA, Jorge Bondía. Notas sobre a experiência e o saber de experiência. Tradução de João Wanderley Geraldi. Revista Brasileira de Educação, São Paulo, n. 19, p.20-28, jan./abr. 2002.

LEMINSKI, Paulo. Caprichos e relaxos. São Paulo: Brasiliense, 1983.

MOISÉS, Massaud. Dicionário de termos literários. São Paulo: Cutrix, 2004. PERRONE-MOISÉS, Leyla. Flores da escrivaninha. São Paulo: Companhia das Letras, 2006.

SANT'ANNA, Sérgio. O embrulho da carne. In: O Vôo da Madrugada. São Paulo: Companhia das Letras, 2003. p. 56 - 71.

SIQUEIRA, João. Organização textual da narrativa. São Paulo: Selinunte, 1992. 